\title{
ORGANIZAÇÕES SOCIAIS: UMA PROPOSTA PARA ADMINISTRAÇÃO PÚBLICA EFICIENTE
}

\section{ARTIGO ORIGINAL}

COSTA, Maria Clarice Alves da ${ }^{1}$, SANTOS, Evanice dos ${ }^{2}$, VALE, Dimas Vitor Moret do ${ }^{3}$, SILVA, Eliane Alves da ${ }^{4}$, SILVA, Klebson Leonardo de Souza ${ }^{5}$

COSTA, Maria Clarice Alves da. Et al. Organizações sociais: uma proposta para administração pública eficiente. Revista Científica Multidisciplinar Núcleo do Conhecimento. Ano 06, Ed. 07, Vol. 01, pp. 99-113. Julho de 2021. ISSN: 2448-0959, Link de acesso: https://www.nucleodoconhecimento.com.br/administracao/publicaeficiente, DOI: 10.32749/nucleodoconhecimento.com.br/administracao/publicaeficiente

\section{RESUMO}

O presente artigo tem por objetivo mostrar a inovação da administração pública por meio da instituição das Organizações Sociais - OS como proposta da nova administração pública gerencial, cujo delineamento do tema será o qualitativo narrativo. O estudo transcorre acerca do momento histórico do país, bem como da urgente necessidade de se implantar um modelo de administração gerencial no Brasil. Far-se-á um estudo das entidades qualificadas como Organizações Sociais, em resposta à proposta da administração gerencial, por meio da publicização do setor público frente a instituição da Lei n. 9.637/1998, e o desfecho se dará com a apresentação da conclusão do tema, demonstrando a necessidade de controles desde a caracterização de tais entidades até na aplicação de recursos públicos que

\footnotetext{
${ }^{1}$ Pós-Graduação Licitação Pública; Pós Graduação Lato Sensu Administração Pública; Especialização em Administração Financeira, Administração.

2 Doutora em Ciência Política, Mestre em Gestão e Desenvolvimento Regional, Licenciatura Plena em Pedagogia.

${ }^{3}$ Bacharel em Ciências Jurídicas.

${ }^{4}$ Mestre em Administração pela Universidade Federal de Rondônia.

${ }^{5}$ Especialista pela Faculdade Damásio e pela Faculdade Pólis Civitas.
}

RC: 90278

Disponível em: https://www.nucleodoconhecimento.com.br/administracao/publicaeficiente 
são repassados a essas organizações e com sugestão estudos futuros acerca de como é se dá controle por parte da Administração Pública dos recursos repassados às Organizações Sociais.

Palavras-chave: Administração pública gerencial, Publicização, Organizações Sociais.

\section{INTRODUÇÃO}

Dadas às dificuldades em que o país se encontra, em razão de grandes gastos com a máquina pública, o crescente endividamento e a crise fiscal, buscou-se como resposta a esse esgotamento do setor público, a incorporação de um novo conceito de administrar. Assim, foi no setor privado que se espelhou o novo modelo gerencial para ser aplicado ao setor público. Nesse sentido, foi estabelecida a nova era na administração pública; a implantação da administração gerencial, voltada para a eficiência e a qualidade, descentralizada e com foco no cidadão.

O novo modelo de gerencialismo público propõe quatro setores para o Estado e a cada um são atribuídas atividades específicas. Uma destas formas é a de serviços não exclusivo, em que tais atividades deveriam ser transferidas para as entidades não estatais, segundo o Plano Diretor elaborado por Bresser Pereira (MARE, 1998c).

A chamada publicização foi iniciada com o Plano Diretor da Reforma do aparelho estatal, que foi elaborado pelo Ministério da Administração Federal e da Reforma do Estado - MARE e aprovado pela Câmara da Reforma do Estado em reunião de 21.9.1995, segundo DI PIETRO (2002, p. 419). Contudo, As Organizações sociais foram instituídas e definidas pela Lei n. 9.637 de 15.05.1998.

A nova nomenclatura - publicização - teve como objetivo tornar o serviço público, até então fornecido pelo Estado, em uma atividade não exclusiva estatal. Esta transferência consiste na efetiva transformação de instituições públicas em organizações privadas sem fins lucrativos, celebrando um contrato de gestão específico com o Poder Executivo para que estas novas instituições privadas de

RC: 90278

Disponível em: https://www.nucleodoconhecimento.com.br/administracao/publicaeficiente 
caráter público, denominadas organizações sociais - OS, tenham acesso a recursos orçamentários do governo.

Embora constituídas como entidades privadas sem fins lucrativos, as OS permanecem sob o controle do Estado, seja pela participação de membros do governo nos conselhos de direção destas entidades, seja pelos requisitos de monitoramento de impostos nos contratos de gestão.

O pressuposto do programa de publicização é que os serviços públicos não-exclusivos podem ser realizados mais eficientemente por entidades qualificadas para este fim; e serem mantidas por meio transferências de recursos públicos, por meio da assinatura de contrato de gestão. E como vantagens atribuídas às organizações sociais estão: a sua operação com maior autonomia, a possibilidade de controle social direto da sociedade, a eficiência de gestão e a qualidade dos serviços que estas oferecem.

Esta pesquisa se propõe a mostrar a inovação na administração pública por meio da instituição de OS como proposta da nova administração pública gerencial.

Para elaborar o estudo, foram estabelecidos 3 (três) objetivos específicos. O primeiro será descrever a Administração Pública vertendo para o campo do gerencialismo, quando do Plano Diretor da Reforma do Aparelho Estatal - PDRAE; o segundo, analisar o gerencialismo da nova adminstração com a instituição de novas entidades instituidas para atuarem nos serviços não exclusivos e por útlimo estudar os diversos pontos da Lei n. 9.367/1988 que instituiu as Organizações Sociais - OS.

Esta pesquisa tem relevância social e econômica. Como relevância social, favorece discussões e reflexões, acerca da participação de entidades privadas na prestação de serviço do público; como relevância econômica, está o fato de que as entidades qualificadas com organizações sociais recebem repasse de recursos públicos e o uso de bens públicos. 
Como procedimento metodológico, ter-se-á a consulta à Lei da instituição das Organizações Sociais e levantamento bibliográfico para enumerar os diversos entendimentos sobre o tema.

\section{A ADMINISTRAÇÃO PÚBLICA RUMO AO GERENCIALISMO}

Há um grande desafio na atualidade quanto às mudanças do cenário global, fato que desafia a sociedade e o Estado. Na conjuntura atual faz-se necessário repensar a administração pública, no que diz respeito tanto ao sistema econômico quanto ao político. O rever remete a uma necessidade de reorganização do Estado diante da realidade que se encontra.

Segundo Cardoso (2003, p. 15) mudar o Estado significa abandonar visões do passado de um Estado assistencialista e paternalista; de um Estado que se concentrava em larga escala em ações de produção de bens e de serviços. Por essa visão, entende-se que o setor produtivo deve ser transferido à sociedade, à iniciativa privada, pelo fato de serem mais eficientes e conseguirem redução de custo ao consumidor.

O primeiro impulso da Nova Gestão Pública - NPM se deu mediante o gerencialismo puro (ou managerialism - em inglês). De acordo com Abrucio (1997), a Inglaterra, no governo Thatcher em 1979, foi um dos primeiros países a adotar os conceitos do NPM. Em razão da exaustão das finanças do Estado e de incapacidade em atender a todas as reivindicações sociais que a sociedade demandava. As primeiras ações foram reduzir custos e pessoal. Diz esse autor que o objetivo era devolver ao Estado a condição de investir por meio de redução de custos e do aumento da eficiência. No contexto, havia estratégia de reposicionar o papel do Estado na sociedade, reduzindo o número de atividades. O primeiro impulso foi orientado para melhora das finanças e da produtividade dos órgãos públicos.

A burocracia vista como excessivamente rígida e centralizadora à época, tornava o Estado lento às demandas do meio externo. A visão que se tinha do setor público era

RC: 90278

Disponível em: https://www.nucleodoconhecimento.com.br/administracao/publicaeficiente 
de somente do cumprimento de regras e regulamentos, e não de resultados (ABRUCIO, 1997). O autor, ainda, diz que dentre as iniciativas de Thatcher foram a privatização, a desregulamentação, a redução de cargos públicos, a definição clara dos objetivos de cada setor e outras com o intuito de reduzir os gastos. O movimento ficou conhecido como rolling back the state, algo como "retração da máquina estatal". 9674151591

De acordo com Paula (2005) as características principais desse modelo foram descentralizar o aparelho estatal, que segregou as atividades de planejamento e execução das atividades e transferiu para os ministérios como monopólio das políticas públicas; realizou a privatização das estatais; efetuou a terceirização dos serviços públicos; regulamentou as atividades públicas conduzidas pelo setor privado e aplicou as ideias e ferramentas gerenciais utilizadas naquele setor.

Segundo Bresser Pereira (2003, p. 28), a administração pública gerencial emergiu na segunda metade século $\mathrm{XX}$, em resposta à crise do Estado, como estratégia para reduzir o custo e tornar mais eficiente a administração e como proteção do patrimônio público contra os interesses do rent-seeking ou da corrupção aberta.

O Plano Diretor da Reforma do Aparelho Estatal - PDRAE, trouxe uma nova proposta, segundo Bresser Pereira (2003, p. 28):

A administração pública gerencial constitui um avanço e até um certo
ponto um rompimento com a administração pública burocrática. Isto
não significa, entretanto, que negue todos os seus princípios. Pelo
contrário, a administração pública gerencial está apoiada na anterior,
da qual conserva, embora flexibilizando, alguns dos seus princípios
fundamentais, como a admissão segundo rígidos critérios de mérito, a
existência de um sistema estruturado e universal de remuneração, as
carreiras, a avaliação constante de desempenho, o treinamento
sistemático. A diferença fundamental está na forma de controle, que
deixa de basear-se nos processos para concentrar-se nos resultados,
e não na rigorosa profissionalização da administração pública, que
continua um princípio fundamental.

Dentre os atributos que delineiam a administração gerencial têm-se como alvo o cidadão, como beneficiário dos serviços do estado e obtenção de resultados pelos 
gestores (BRESSER PEREIRA, 2003). Em resposta a nova meta do Estado gerencial a estratégia foi de descentralizar, de incentivo à criatividade e inovação e como instrumento de controle, o contrato de gestão. De acordo com Bresser (2003, p. 28), o modelo gerencial prega que o Estado deveria ter um grau de confiança limitado em relação aos seus servidores: "[...], algumas características básicas definem a administração pública gerencial. [...] orientada para o cidadão e para a obtenção de resultados e pressupõe que os políticos e os funcionários públicos são merecedores de um grau real ainda que limitado de confiança."

A administração gerencial tem como ideia central descentralizar, delegar autoridade; para isto Bresser Pereira (2003, p. 33) diz que os Estados modernos contam com quatro setores: o núcleo estratégico, as atividades exclusivas, os serviços não exclusivos e a produção de bens e serviços para o mercado. O núcleo estratégico é o que define as leis e as políticas e como as fazer cumprir, que está vinculado os Poderes Legislativo e Judiciário, ao Ministério Público e ao Poder Executivo; referese ao Governo em sentido amplo. Enquanto as atividades exclusivas englobam as atividades típicas de poder de Estado, que dão suporte para que as leis e políticas públicas sejam cumpridas e financiadas, ou seja, o poder de regulamentar, fiscalizar e fomentar.

Os serviços não exclusivos são os que o Estado provê, mas também podem ser oferecidos pelo setor privado e pelo setor público não estatal. As instituições desse setor não possuem poder de Estado, porém se faz presente, porquanto tais serviços referem aos direitos fundamentais, como educação e saúde. Os setores envolvidos são as universidades, os hospitais, os centros de pesquisa e os museus.

E, o setor de produção de bens e serviços formados por empresas estatais do segmento produtivo ou do mercado financeiro. São atividades voltadas para o lucro, que são oferecidas pelo Estado. Contudo, este setor a regra que seja propriedade privada, dada que tais atividades são exclusivas de mercado. Só se justifica a participação do Estado quando à inexistência de capital privado disponível ou no caso

RC: 90278

Disponível em: https://www.nucleodoconhecimento.com.br/administracao/publicaeficiente 
de monopólio natural, que poderia ter a gestão privada e apenas acompanhada por um sistema seguro de regulação.

A reforma do Estado usou a técnica da "publicização", dos serviços não-exclusivos do Estado, isto é, o setor público não estatal absorve tais serviços, e o Estado apenas fomenta por meio das organizações sociais (MARE, 1998c).

O Estado firma uma parceria com a sociedade, com o objetivo de viabilizar a ação pública, dando mais agilidade e maior alcance, tornando mais fácil e direto o controle social, mediante a participação, nos conselhos de administração, dos diversos segmentos beneficiários envolvidos.

São objetivos, relativamente aos serviços não-exclusivos a transferência de serviços não-exclusivos, por meio de programas em que possibilita que organizações sociais qualificadas possam desempenhar as atividades; tais entidades terão maior autonomia e flexibilidade, no entanto os dirigentes serão responsáveis pelas atividades desempenhadas; o cidadão poderá exercer maior controle social, e por fim, os serviços serão baseados em resultados.

As organizações nesse setor gozam de uma autonomia administrativa maior em relação ao Estado, quando está executando as mesmas ações. Contudo, nas novas organizações, seus dirigentes são chamados a assumir uma responsabilidade maior, em conjunto com a sociedade, na gestão da instituição. Bresser Pereira (2003, p. 29) usa o termo privatização, que traz a ideia de transferência de recursos públicos a entidades não estatais, para que estas assumam as atividades não-exclusivas de Estado. Assim, a ideia de publicizar visa atender melhor o usuário do serviço público, cidadão-cliente, por meio da eficiência e a qualidade dos serviços.

\section{ORGANIZAÇÕES SOCIAIS}

As Organizações Sociais - OS, no âmbito do Programa Nacional de Publicização PN, são pensadas dentro da lógica da Administração Gerencial, com o objetivo de prestação de serviço não-exclusivo, por meio da descentralização da atuação do

RC: 90278

Disponível em: https://www.nucleodoconhecimento.com.br/administracao/publicaeficiente 
Estado. O objetivo é transferir atividades ou serviços não exclusivos do Estado para organizações privadas sem fins lucrativos, o pensamento é de que tais serviços seriam prestados com mais qualidade, otimizados quanto à utilização dos recursos e com ênfase nos resultados (MARE, 1998c). De acordo com o Plano Diretor da Reforma do Aparelho Estatal - PDRAE, as Organizações Sociais eram definidas como:

O Projeto das Organizações Sociais tem como objetivo permitir a descentralização de atividades no setor de prestação de serviços não exclusivos, nos quais não existe o exercício do poder de Estado, a partir do pressuposto que esses serviços serão mais eficientemente realizados se, mantendo o financiamento do Estado, forem realizados pelo setor público não estatal.

Entende-se por "organizações sociais" as entidades de direito privado que, por iniciativa do Poder Executivo, obtêm autorização legislativa para celebrar contrato de gestão com esse poder, e assim ter direito à dotação orçamentária.

As organizações sociais terão autonomia financeira e administrativa, respeitadas condições descritas em lei específica como, por exemplo, a forma de composição de seus conselhos de administração, prevenindo-se, deste modo, a privatização ou a feudalização dessas entidades. Elas receberão recursos orçamentários, podendo obter outros ingressos através da prestação de serviços, doações, legados, financiamentos, dentre outros. Grifo nosso.

As Organizações Sociais foram instituídas pela Lei n. 9.637, de 15 de maio de 1998. A referida norma dispõe sobre a qualificação de entidade como organizações sociais, a criação do Programa de Publicização, a extinção dos órgãos e entidades que menciona e a absorção de suas atividades por organizações sociais. Embora as OS sejam novidade institucional, não constituem inovação jurídica, inserem-se no mundo legal sob a forma de associações civis sem fins lucrativos.

A qualificação como entidades jurídicas de direito privado, sem fins lucrativos é discricionária do Poder Executivo, que poderá ser em atividades dirigidas ao ensino, à pesquisa científica, ao desenvolvimento tecnológico, à preservação do meio ambiente, à cultura e à saúde, atendidos os requisitos da Lei n. 9.637/1998.

RC: 90278

Disponível em: https://www.nucleodoconhecimento.com.br/administracao/publicaeficiente 
Para que as entidades privadas habilitem à qualificação como organização social deverão comprovar dentre os requisitos de que os objetivos da natureza social são relativos à respectiva área de atuação. A finalidade não lucrativa, com a obrigatoriedade de que os excedentes financeiros sejam investidos no desenvolvimento de suas próprias atividades; previsão expressa de composição de órgãos superiores deliberativos e de direção, conselho de administração e diretoria definida nos termos do estatuto; obrigatoriedade de publicação anual dos relatórios financeiros e de execução do contrato de gestão no Diário Oficial da União; haver aprovação, quanto à conveniência e oportunidade de sua qualificação como organização social, do Ministro ou titular de órgão supervisor ou regulador da área de atividade correspondente ao seu objeto social e do Ministro de Estado da Administração Federal e Reforma do Estado.

Segundo Marinela, (2016, p. 237) os Estados e Municípios, por sua vez, poderão criar organizações sociais, desde que aprovem suas leis próprias, em que a competência seja dada a cada entidade estatal. A Lei n. 9.637/98 é restrita ao âmbito federal; contudo, o normativo da União poderá servir de parâmetro para as outras esferas, devendo ser adaptado às peculiaridades regionais.

No que concerne à outorga da qualificação às Organizações Sociais, constitui decisão discricionária, conveniência e oportunidade do Ministro ou titular de órgão superior. Pode-se dizer que gera apenas uma expectativa de direito quanto ao referido pleito. Contudo, Celso Antônio Bandeira de Melo (1996, p. 16) leciona que:

\begin{abstract}
A lei, ao regular as várias possíveis situações a ocorrerem no mundo real, pode disciplinar a conduta do agente público estabelecendo de antemão e em termos estritamente objetivos, aferíveis objetivamente, quais as situações de fato que ensejarão o exercício de uma dada conduta e determinando, em seguida, de modo completo, qual o comportamento único que, perante aquela situação de fato, tem que ser obrigatoriamente tomado pelo agente. Neste caso, diz-se que existe vinculação porque foi pré-traçada pela regra de Direito a situação de fato, e o foi em termos de incontendível objetividade, prescrevendo-se, ainda, o dever de adotar perante ela um comportamento já estabelecido de antemão.
\end{abstract}

Celso Antônio Bandeira de Melo (1996, p. 15) esclarece que:

RC: 90278

Disponível em: https://www.nucleodoconhecimento.com.br/administracao/publicaeficiente 
[...] o chamado "poder discricionário" tem que ser simplesmente o cumprimento do dever de alcançar a finalidade legal. Só assim poderá ser corretamente entendido e dimensionado, compreendendo-se, então, que o que há é um dever discricionário, antes que um "poder" discricionário. Uma vez assentido que os chamados poderes são meros veículos instrumentais para propiciar ao obrigado cumprir o seu dever, ter-se-á da discricionariedade, provavelmente, uma visão totalmente distinta daquela que habitualmente se tem.

Malgrado a lei mencionar a discricionariedade na qualificação, é relevante observar que o fato de o gestor ter a opção de conceder o título ou não a uma empresa, pode ir de encontro ao princípio da isonomia. O que se espera é que seja interpretado como um ato meramente declaratório da observância dos requisitos exigidos. Di Pietro (2012) menciona os requisitos mínimos que seriam necessários para que as organizações sociais se enquadrem nos princípios constitucionais a exigência de licitação para a escolha da entidade; comprovação e existência e requisitos exigidos para cumprimento das atividades, idoneidade financeira e qualificação técnica; submissão aos procedimento licitatório; imposição de limites de salários quando houver participação de recursos público e garantias que irá cumprir os contratos administrativos com o poder público.

Apresentado todos os requisitos, estes serão submetidos a posterior aprovação, que será baseada na conveniência e oportunidade do interesse público, e será chancelado pelo Ministro ou titular supervisor da sua área correspondente (DI PIETRO, 2012). Pode se inferir que o procedimento de qualificação não se limita ao arbítrio do administrador. Deve-se repensar o subjetivismo e clara a definição das hipóteses a serem analisadas no ato de se conceder a qualificação às empresas que pleiteiam o título de Organização Social, para que as escolhas não sejam a margem do interesse público. Ponto relevante a se destacar é o artigo $5^{\circ}$ da Lei n. 9.637/1998, que trata do contrato de gestão, in verbis:

Art. 5․ Para os efeitos desta Lei, entende-se por contrato de gestão o instrumento firmado entre o Poder Público e a entidade qualificada como organização social, com vistas à formação de parceria entre as partes para fomento e execução de atividades relativas às áreas relacionadas no art. $1^{\circ}$.

RC: 90278

Disponível em: https://www.nucleodoconhecimento.com.br/administracao/publicaeficiente 
A Organização Social que assumir quais sejam os objetivos: ensino, pesquisa científica, desenvolvimento tecnológico, preservação do meio ambiente, cultura e saúde poderá celebrar contrato de gestão com a Administração Pública, observado os requisitos dispostos no artigo $2^{\circ}$ da lei que trata da qualificação de entidades como organizações sociais. Quando da delegação do serviço público a tais entidades sociais, há de se verificar se são pessoas jurídicas do direito privado, essencialmente sem fins lucrativos. Contudo, poderá gerar lucros, mas tais ganhos devem ser aplicados na atividade fim da organização. Marçal Justen Filho (2006, p. 304) diz que:

O contrato de gestão pode gerar uma delegação de serviço público, entendida a expressão em sentido amplo. Mas organização social nunca pode ser assemelhada a uma concessionária de serviço público, que atua buscando o lucro. A organização social não visa o lucro, ainda que possa obtê-lo como decorrência de sua eficiência.

O contrato de gestão, só será obrigatório quando da qualificação específica em Organização Social, que deverá estipular o cronograma de atividades, seu objeto, bem como seus programas de metas a serem alcançados. Segundo Meirelles, (2001, p. 356), os bens a essas entidades serão transferidos mediante permissão de uso e os recursos serão liberados de acordo com o cronograma de desembolso estabelecidos no mencionado contrato de gestão.

Quanto à dispensa de licitação as entidades se valem da regra do artigo 24 , inciso XXIV, da Lei Federal n. 8.666/93, que garante a contração pela Administração de organizações sociais, que segundo Marinela (2016, p. 238), não acontece em outro caso de transferência de serviços públicos não exclusivos, colocando em risco a transparência da atividade administrativa e facilitando o desvio de dinheiro público.

Ainda referente à dispensa de licitação das Organizações Sociais, Celso Antônio Bandeira de Mello adota o seguinte pensamento (2004, p. 223):

A tentativa do legislador, partindo da boa-fé, em admitir a dispensa de licitação foi a de tentar encontrar novos caminhos para que serviços públicos fossem prestados de forma efetiva sem que esbarrassem nos entraves burocráticos que permeiam nosso ordenamento jurídico administrativo brasileiro, colocando o princípio da eficiência em

RC: 90278

Disponível em: https://www.nucleodoconhecimento.com.br/administracao/publicaeficiente 
prática, já que por diversos anos a Administração Pública comprovou a sua ineficiência na prestação desses.

A não submissão ao processo licitatório, por outro lado, abre possibilidade de que entidades sejam instituídas com aparência social, com o intuito do desvio de recursos públicos. Há de ponderar ainda que, quando há concorrência pública não ocorram desvios, pois em razão de a fiscalização do cumprimento de metas só ocorrer posteriormente, pode dificultar o controle, bem como a recuperação dos recursos desviados. Para Marçal Justen Filho (2004, p. 31), faz-se necessária prévia licitação para configurar o contrato de gestão e escolha da entidade privada a ser contratada. Assim, uma vez firmado o referido contrato de gestão, as futuras contratações de prestação de serviço - já previamente identificadas - serão pactuadas sem necessidade de nova licitação; refere-se o autor aos contratos instrumentais relacionados ao contrato de gestão.

A qualificação Organização Social é temporária, vigente enquanto existir o contrato. Contudo, em razão de descumprimento das cláusulas do contrato de gestão, a entidade perderá a denominação e os benefícios aos quais eram beneficiadas. Para o desfazimento do contrato com a administração será obrigatório o processo administrativo prévio, com o contraditório e a ampla defesa. Para José dos Santos Carvalho Filho (2005, p. 269), uma vez realizada a desqualificação, os dirigentes serão responsabilizados de forma solidária pelos prejuízos que tiverem ocasionado ao Poder Público; com a reversão dos bens usados nas permissões de uso, bem como o ressarcimento dos recursos disponibilizados, além de todas as sanções previstas.

Ainda, José dos Santos Carvalho Filho (2005, p. 270) leciona que, para o êxito das organizações sociais, por consequência o contrato de gestão, é necessária uma fiscalização efetiva nas entidades e no cumprimento de seus objetivos, porquanto, segundo o autor, a falta do controle poderá gerar situações de descontrole das atividades administrativas, desnorteamento dos objetivos estipulados e facilitação do cometimento de crimes contra o sistema financeiro do país.

RC: 90278

Disponível em: https://www.nucleodoconhecimento.com.br/administracao/publicaeficiente 
Lester (1998) sustenta que o "desafio central" para os administradores de organizações sem fins lucrativos não é simplesmente aperfeiçoar a gestão de suas organizações, mas encontrar soluções para os problemas públicos por meio da gestão de relacionamentos colaborativos complexos que se estabelecem entre os setores e que tendem a se tornar mais comuns em todo o mundo.

Por fim, a solução de problemas na gestão das entidades sociais deve resgatar a interdisciplinaridade do campo de Administração, trazendo da administração de empresas a visão de negócio, da administração pública a competência de gestão de serviços públicos, mas também do campo de políticas públicas o sentido de capacitar para o atingimento de objetivos públicos e não exclusivamente organizacionais. A perspectiva dos problemas públicos e das políticas públicas deve estar na mente do administrador de tais entidades, tanto quanto os problemas imediatos de sobrevivência de suas organizações (LESTER, 1998).

\section{CONCLUSÃO}

O enfoque da proposta da administração gerencial na Administração Pública se deu em um momento de crise econômica e fiscal do país. O novo conceito da Nova Gestão Pública - NPM foi trazido da Inglaterra, como modelo adotado no governo Thatcher em 1979. No Brasil a nova gestão pública foi proposta por Bresser Pereira como Plano Diretor da Reforma do Aparelho Estatal - PDRAE, no governo de Fernando Henrique Cardoso.

A administração gerencial tem como ideia central descentralização das atividades de Estado e a delegação de autoridade. Para avançar para a nova proposta da Administração Pública, Bresser Pereira (2003) desenha o cenário do Estado contando com quatro setores: o núcleo estratégico, as atividades exclusivas, os serviços não exclusivos e a produção de bens e serviços para o mercado.

O núcleo estratégico seria aquele que define as leis e as políticas e como as fazer cumprir. Enquanto as atividades exclusivas englobam as atividades típicas de poder

RC: 90278

Disponível em: https://www.nucleodoconhecimento.com.br/administracao/publicaeficiente 
de Estado, que dão suporte para que as leis e políticas públicas sejam cumpridas e financiadas. Os serviços não exclusivos são os que o Estado provê, mas também podem ser oferecidos pelo setor privado e pelo setor público não estatal. E, por último, o setor de produção de bens e serviços formados por empresas estatais do segmento produtivo ou do mercado financeiro.

O contexto apresentado para este estudo restou limitado aos serviços não exclusivos, que foi abordado acerca das entidades, cujas características são definidas como Organizações Sociais, que fora instituída e definida pela Lei Federal n. 9.637/1988.

As empresas que recebem a qualificação de Organizações Sociais são entidades sem fins lucrativos e devem possuir alguns requisitos e suas atividades serem voltadas ao ensino, à pesquisa científica, ao desenvolvimento tecnológico, à preservação do meio ambiente, à cultura e à saúde; contudo, tal qualificação é discricionária do Poder Executivo.

A discricionariedade em conceder a qualificação das entidades que cumprem os requisitos para adquirirem o título de Organização Social, pelo gestor, deverá estar pautada nos parâmetros legais, em razão de que deve haver preocupação por parte do responsável, em relação ao princípio de isonomia dando oportunidade às entidades que cumprem os requisitos e rechaçar as possíveis benesses àquelas entidades que tentam se qualificar para beneficiar apenas do recurso público.

Há controvérsia quanto ao fato de tais entidades não se submeterem a prévia licitação para a escolha da entidade privada a ser contratada. Pelo fato de que pode haver suposta contratação de empresas com meios escusos, somente para o desvio de dinheiro público, possibilitando assim a corrupção.

As Organizações Sociais firmam contrato de gestão, com o Ministério ao qual é vinculada a atividade fim da entidade, que deverá estipular o cronograma de atividades, seu objeto, bem como seus programas e metas a serem alcançados.

RC: 90278

Disponível em: https://www.nucleodoconhecimento.com.br/administracao/publicaeficiente 
Por fim, no que pese ao interesse público, o contrato de gestão se faz necessário quando da contratação das Organizações Sociais, pois é o instrumento que viabiliza a publicização das metas dos planos de Estado. Embora, se mostre um instrumento eficaz, não harmoniza com a transparência administrativa por conta da ausência de certos institutos burocráticos.

Por mais que as mudanças de paradigmas de uma nova gestão atuem em nossa sociedade, pleiteando maior eficiência e rapidez na prestação de serviços públicos, ainda assim há o entendimento que certos ritos deverão ser observados quando do momento da seleção dessas entidades, porquanto não se olvida que está se tratando de recursos públicos.

Ademais, deve se cercar de mecanismos de prudência na aplicação desses recursos, por isso faz-se necessário um procedimento mais rigoroso, ou seja, que haja um processo licitatório no momento da escolha da entidade, para que possa diminuir as possibilidades de desvio de verbas públicas.

Com tudo isso, entende-se que o contrato de gestão é positivo para o nosso sistema jurídico; contudo, observando todas as possibilidades de danos ao erário, utilizandose das ferramentas de controle existente na Administração Pública. Ainda, a observância de preceitos de ordem pública deve considerada, já que o interesse público deve ser salvaguardado, bem como a qualidade na prestação de serviço ou entrega de bens ao cidadão. Como proposta de estudos futuros propõe-se estudos acerca de como é o controle por parte da Administração Públicas dos recursos repassados às Organizações Sociais.

\section{REFERÊNCIAS}

ABRUCIO, Fernando Luiz. O impacto do modelo gerencial na Administração Pública: Um breve estudo sobre a experiência internacional recente. Caderno ENAP n¹0, 52, 1997.

RC: 90278

Disponível em: https://www.nucleodoconhecimento.com.br/administracao/publicaeficiente 
ALEXANDRINO, Marcelo; PAULO, Vicente. Direito Administrativo. 4.ed. Rio de Janeiro: Impetus, 2002.

BANDEIRA DE MELLO, Celso Antônio. Curso de Direito Administrativo. 17.ed. São Paulo: Malheiros, 2004.

BANDEIRA DE MELLO, Celso Antônio. Discricionariedade e Controle Jurisdicional. 1ํ Edição, Malheiros Editores Ltda, São Paulo, 1996.

BRASIL. 1998. Plano Diretor da Reforma do Aparelho do Estado. Brasília: Presidência da República. BRASIL. Organizações Sociais. Série Cadernos Mare da Reforma do Estado, № 2. Brasília: MARE, 1995.

BRESSER PEREIRA, L. C. Do Estado Patrimonial ao Gerencial. In: W. e. Pinheiro, Brasil: um século de transformações. São Paulo: Cia das Letras, 2001. 222-259 p.

BRESSER PEREIRA, L. Uma reforma gerencial da Administração Pública no Brasil. Revista do Serviço Público, 1998. 5-41 p.

CADERNOS MARE DA REFORMA DO ESTADO. 1997. Organizações Sociais, Caderno 2, Ministério da Administração Federal e Reforma do Estado, Brasília-DF, 1997. $3 \mathrm{p}$

CARVALHO FILHO, José dos Santos. Manual de Direito Administrativo. 13.ed. Rio de Janeiro: Lúmen Júris, 2005.

Constituição

Federal/1998.

Disponível

em: http://www.planalto.gov.br/ccivil_03/constituicao/constituicaocompilado.htm. Acesso em 15.12.2020.

DI PIETRO, Maria Sylvia Zanella. Parcerias na Administração Pública. São Paulo, SP: Atlas, 2012.

RC: 90278

Disponível em: https://www.nucleodoconhecimento.com.br/administracao/publicaeficiente 
DI PIETRO, Maria Sylvia Zanella. Direito Administrativo. 14.ed. São Paulo: Atlas, 2002.

JUSTEN FILHO, Marçal. Curso de Direito Administrativo. 2.ed. São Paulo: Saraiva, 2006.

Lei n. 9.367/1998. Disponível http://www.planalto.gov.br/CCivil_03/leis/L9637.htm. Acesso em 15.12.2020.

LESTER M. Salamon. "Nonprofit Management Education: A Field Whose Time Has Passed?", in Michael O'Neill \& Kathleen Fletcher, Nonprofit Management Education: U.S. and World Perspectives, Westport: Praeger, 1998.

MARE. Avanços da reforma na Administração Pública (1995-1998). Cadernos MARE, n. 15, 1998c. 129 p.

MARINELA, Fernanda. Direito Administrativo. 10 ed. - São Paulo: Saraiva, 2016.

MEIRELLES, Hely Lopes. (2001). Direito Administrativo Brasileiro. 26.ed. São Paulo: Malheiros, 2001.

PAULA, A. P. (2005). Por uma nova gestão pública: limites e potencialidades da experiência contemporânea. Rio de Janeiro: FGV.

VIEIRA, E. A Constituição de 1988 e o novo cenário político-social do Brasil. In: LOPES, J.R. (Org.). O processo de democratização na sociedade brasileira: 20 anos de luta pela cidadania. São Paulo: Sesc; Nepps-Unitau, 1999.

Enviado: Fevereiro, 2021.

Aprovado: Junho, 2021.

RC: 90278

Disponível em: https://www.nucleodoconhecimento.com.br/administracao/publicaeficiente 